\title{
Genetics of a colour polymorphism in Theridion grallator (Araneae: Theridiidae), the Hawaiian happy-face spider, from Greater Maui
}

\author{
G. S. OXFORD* \& R. G. GILLESPIE $\dagger$ \\ Department of Biology, University of York, PO Box 373, York YO1 5YW, U.K. and †Center for Conservation Research \\ and Training, University of Hawaii, 3050 Maile Way, Gilmore 310, Honolulu, HI 96822, U.S.A.
}

\begin{abstract}
Theridion grallator, the Hawaiian happy-face spider, a species endemic to four islands in the Hawaiian archipelago, exhibits an exuberant colour and pattern polymorphism involving both the carapace and opisthosoma (abdomen). Laboratory crosses and broods from wild-mated females demonstrate that the opisthosomal morphs on Maui (and probably on Moloka'i as well) act as if they are determined by alleles at one autosomal locus, although control by more than one linked locus cannot be eliminated. With the exception of the White morph, dominance results from the superimposition of one pattern on another. All morphs are found equally in males and females. Carapace morphs are also shown to be determined by alleles at one locus. The close association between particular carapace and opisthosomal patterns observed both in the field and in the laboratory is probably a result of linkage between loci rather than pleiotropic effects of alleles at one locus. A one-to-one matching of red- and blackpigmented areas on the opisthosoma with underlying guanine deposits, which produce a white backcloth against which the pigments are displayed, strongly suggests that the polymorphism in this species has evolved for its visual effects.
\end{abstract}

Keywords: colour polymorphism, Hawaii, spider, supergene, Theridion grallator.

\section{Introduction}

Polymorphisms for colour and pattern have long attracted the attention of evolutionists (e.g. Gulick, 1872,1873 ) as they provide tractable systems conducive to advancing our knowledge and understanding of evolutionary processes. Indeed, for decades they were the only means with which to examine evolutionary changes at specific loci. Despite the advent of molecular techniques, visible polymorphisms continue to be useful in this respect by offering the opportunity to identify, without intrusion, genotypically discrete variants in natural populations that are likely to be under the influence of selective processes.

Notable successes of this approach include studies on the evolution of melanism in Biston betularia, the peppered moth, which have shed light on the adap-

${ }^{*}$ Correspondence. tive nature of shifts in coloration in response to a changing background, the strength and nature of some of the selective forces involved and how dominance can evolve (Kettlewell, 1973). Although in many cases visible variation is simply controlled by alleles at one locus, other examples are more complex and involve a number of tightly linked loci (a supergene) each contributing to a different element of the overall colour and pattern. Examples of this are to be found in the land snails Cepaea nemoralis and $C$. hortensis (Jones et al., 1977), the mimetic butterflies Papilio dardanus, $P$. polytes and $P$. memnon (Clarke \& Sheppard, 1960a, 1971, 1972; Clarke et al., 1968) and Adalia bipunctata, the two-spot ladybird (Majerus, 1994). Supergenes can evolve by the tandem duplication of loci in situ, perhaps with subsequent divergence in function of the constituent loci, and/or by the accumulation of loci from different parts of the genome. The latter 
process provides prima facia evidence for selection favouring particular combinations of visual elements. This was clearly demonstrated in the classical studies of mimicry in Papilio memnon, a south-east Asian swallowtail butterfly, by Clarke et al. (1968). They showed that in areas where all models had tails, the tail locus in the mimic was unlinked to the supergene controlling the rest of the pattern, whereas in areas where some models had tails and some did not, the tail locus in the mimic was tightly linked within the supergene. They also investigated dominance patterns in the African $P$. dardanus and demonstrated convincingly that dominance can evolve by selection at other, modifier loci in situations in which heterozygotes of intermediate appearance are at a disadvantage (Clarke \& Sheppard, $1960 \mathrm{~b})$. It is possible therefore that a fuller understanding of the nature and genetical control of visible polymorphic systems can shed light on the mode(s) of selection operating on them.

The genetical control of colour polymorphisms has been little studied in spiders although the phenomenon is widespread (Gillespie \& Tabashnik, 1989 and references therein). One of the most spectacular visible polymorphisms in this group is shown by Theridion grallator (Araneae: Theridiidae), the endemic Hawaiian happy-face spider. Theridion grallator is a small species $($ c. $5 \mathrm{~mm})$ recorded from four of the Hawaiian islands, O'ahu, Moloka'i, Maui and Hawai'i (Gon, 1985), where it inhabits the underside of leaves in native wet and mesic forests. It has long, slender legs and an elongated, translucent yellow body with varying numbers of black spots and other marks. In some individuals, superimposed on the opisthosomal (abdominal) background, are patterns of red, black, and white, which yield a very large number of colour morphs (Gon, 1985; Gillespie \& Tabashnik, 1989). Here we analyse the genetical control of the polymorphism in populations from two Hawaiian islands, Maui and Moloka'i. These are known to have once been part of a single landmass (Greater Maui or Maui Nui) which split less than 300000 years ago (Carson \& Clague, 1995). This study represents a step towards elucidating the evolutionary and adaptive significance of this striking polymorphism and extends the previous genetical work of Gillespie \& Tabashnik (1989).

\section{Materials and methods}

Spiders considered here were taken from two populations on the island of Maui and from one on Moloka'i. On Maui, the majority of individuals were sampled in 1993 and 1994 from the Nature Conser- vancy of Hawai'i's Waikamoi Preserve in East Maui, near the common boundary of the Preserve and the Makawao State Forest, altitude $1360 \mathrm{~m}$. A smaller number was sampled in 1994 from Pu'u Kukui in the West Maui Forest reserve, altitude $1387 \mathrm{~m}$. The Moloka'i material was sampled in the vicinity of Pu'u Kolekole in the Nature Conservancy of Hawai'i's Kamakou Preserve, altitude $1110 \mathrm{~m}$. Spiders were found by searching the undersides of leaves of a variety of plants, but particularly the native Broussaisia arguta and Clermontia arborescens, and the introduced Hedychium coronarium, white ginger. Except for maternal females and their progeny, single individuals are found on a leaf. Females guard their egg sacs and remain with the emerged young for between 40 and 100 days, after which the spiderlings disperse (Gillespie, 1990). Genetic information was gathered from two sources, wild-mated females (the male of the cross is therefore unknown) and formal matings set up in the laboratory with virgin females and known males.

Females found with eggs or young were isolated in the laboratory and the young reared. Mature females without progeny were likewise isolated in case they had been inseminated in the wild. Matings established in the laboratory used penultimate instar females and mature males; in nature, males guard such females and mate soon after they moult to maturity (Gon, 1985). Formal matings within Maui were made with Waikamoi material alone. A small number of matings was set up from the Moloka'i population. All spiders were reared in $300 \mathrm{~mL}$ capacity clear plastic drinking cups containing $c .1 \mathrm{~cm}$ depth of coarse sand or fine gravel and sealed with a lid of fine nylon gauze. Water was added to just below the top of the sand or gravel so as to maintain a high humidity within the cup while obviating any danger to the spiders of contact with free water. Cups were maintained in an incubator at $16-18^{\circ} \mathrm{C}$ with a light: darkness cycle of 12:12 h. Each week, spiders were fed on fruit flies (Drosophila melanogaster) and diamond-back moths (Plutella xylostella). Broods reared in Hawai'i also received the endemic fruit-fly, $D$. grimshawi. One major problem encountered was the appearance of predatory mites that attacked and ate spider eggs. To prevent their spread from one brood to another, cups were isolated in shallow trays containing water and detergent. Broods were checked weekly and males identified and removed when their swollen pedipalps became obvious in the penultimate instar. Colour morphs were scored at various stages because different patterns establish at different rates (Gillespie \& Tabashnik, 1989). 


\section{Results}

\section{Description of morphs}

The common, plain yellow opisthosomal morph [named 'unpatterned' by Gillespie \& Tabashnik (1989) but here called Yellow] and 10 others from the Waikamoi population are shown in Plate 1. The names of the morphs and the abbreviations used for each are given in the legend. All but one of the non-plain-yellow (patterned) morphs are produced by the superimposition of red and/or black pigment on the yellow background. These pigments are ommochromes with properties similar to xanthommatin (Oxford, unpublished observations), as is the case in many spiders (Seligy, 1972; Holl, 1987). Ommochrome pigments are deposited in the hypodermis, immediately beneath the cuticle. White is unique among the patterned morphs in that the coloration is a result of a deposit of guanine, a nitrogenous excretory product, in the superficial layers of the gut mass immediately below the hypodermis. The Pu'u Kukui population on Maui, and the population from Moloka'i, contain further morphs not represented in Plate 1.

It is clear from Plate 1 that pigmented marks on the carapace also vary. These are of three types: (i) a black U-shape in the centre of the yellow carapace, (ii) a solid central black bar and (iii) a central bar, the anterior of which is red and the posterior black. There is a tight association between particular opisthosomal patterns and carapace marks. The U-shape is the most common mark, associated with morphs Yellow (Plate 1a), Red front (Plate 1b), Red front + back (Plate 1c), Red blob (Plate 1d), Red ring (Plate 1i), Red/Black blob (Plate 1j) and Red back (Plate $1 \mathrm{k}$ ) followed by the black bar, associated with morphs Black ring (Plate 1e), Red/Black ring (Plate 1f) and White (Plate 1h). The red and black carapace mark is associated with a single morph, Red lines (Plate 1g).

\section{Genetics of opisthosomal morphs - Maui}

As a result of their preliminary work on the genetics of the opisthosomal polymorphism in the Waikamoi population of T. grallator, Gillespie \& Tabashnik (1989) concluded that (i) different patterns segregate in broods in a Mendelian way and (ii) the unpatterned morph (Yellow) is recessive to any patterned morph. Data from present laboratory crosses and from wild-mated females are shown in Tables 1 and 2, respectively, and endorse these features of the genetic system. All morphs are found in approximately equal proportions in males and females, both in field collections (Gillespie \& Tabashnik, 1989; Gillespie \& Oxford, unpublished observations) and in laboratory matings. In those cases where reciprocal matings were made, the outcomes were identical. Sexes have therefore been combined in all further discussion.

Yellow is by far the commonest morph in natural populations (present data; Gillespie \& Tabashnik, 1990) and the vast majority of Yellow females mated in the wild produced all Yellow broods (Table 2, cross nos 25 and 37) which is consistent with this morph being bottom recessive (see analyses by Gillespie \& Tabashnik, 1989). This is confirmed by the results of crosses between Yellow and various patterned morphs (Table 1, nos 2-9) and wildmated yellow females (Table 2, nos 27-30 and 38-40) which either give offspring in a $1: 1$ ratio (Yellow:pattern) or all patterned morphs (Table 1, no. 10; Table 2, nos 31 and 32 ). Finally, and critically, the progeny of most matings between two patterned morphs (Table 1, nos 12-23) contain the Yellow morph.

Cross nos 12-20 (Table 1) involved two patterned parents and yielded progeny segregating in 1:2:1 ratios, indicating that Yellow and the patterned phenotypes appear to be determined by alleles at a single locus. Matings between patterned morphs and Yellow that do not yield Yellow progeny provide information on whether different patterns are controlled by alleles at the same locus. Relevant matings are no. 10 (Table 1), and nos 31 and 32 (Table 2). Additional data on allelism come from matings between patterned morphs; nos 11 and 24 (Table 1), no. 36 (Table 2) and some interisland crosses (Oxford \& Gillespie, 1996b). As a result of these crosses, demonstrated allelism between pairs

Plate 1 Colour morphs of Theridion grallator, the Hawaiian happy-face spider. All individuals are from East Maui. Abbreviations as used in the tables are given after the morph description. Unpatterned morph: (a) Yellow (Yell.). Patterned morphs: (b) Red front (Rfr), (c) Red front + back (Rfr + bk), (d) Red blob (Rblob), (e) Black ring (Bring), (f) Red/Black ring (R/Bring) (note that in the specimen illustrated the ring has yet to fuse at the posterior end), (g) Red lines (Rlines), (h) White, (i) Red ring (Rring), (j) Red/Black blob (R/Bblob), (k) Red back (Rbk), (m) Red ring produced by the interaction of Red lines and Red front + back (see text). The posterior patch on the Red back morph (k) shown here resembles the pattern at the posterior end of the Black ring morph (e), but other Red back individuals have pigmented areas much more like the posterior patch of Red front + back (c). Red- and black-pigmented patterns are underlain by white guanine which is often visible at the edges of the pigment. 

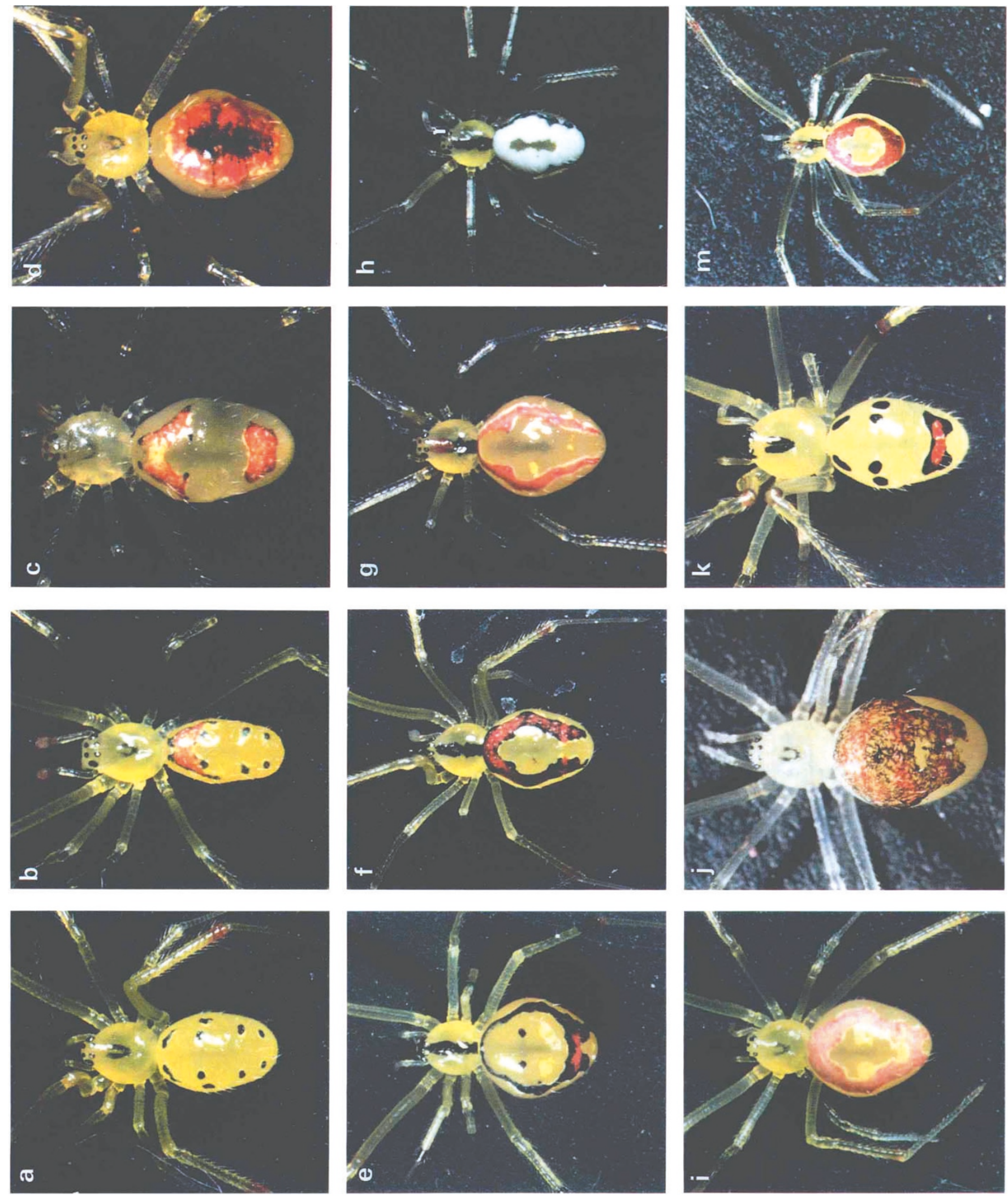

(C) The Genetical Society of Great Britain, Heredity, 76, 238-248. 
of patterned morphs and between patterned morphs and Yellow yield the relationships shown in Fig. 1. Thus nine of the 11 morphs considered here appear to be the products of alleles at one colour locus. The remaining two morphs, Red/Black blob and Red back were wild-mated females (Table 2, nos 41 and 48). The progeny of the former segregated in a good 1:1 ratio, Yellow:Red/Black blob, whereas progeny from the latter cross (no. 48) comprised an odd ratio of phenotypes, but which included some Yellow individuals. Although crosses nos 41 and 48 do not prove that the patterned morphs are allelic to Yellow, they are not inconsistent with this hypothesis. The curious ratio of phenotypes in the brood of no. 48 may reflect the fact that young were scored at a very early stage; high mortality precluded rescoring. From other crosses (Oxford \& Gillespie, 1996a) it is known that the elements of the Red front + back pattern can develop at different rates, so it is possible that some of the individuals scored as Red back would have eventually gained the red pattern at the front as well. Interestingly, Gillespie \& Tabashnik (1989) reported the offspring of a wildmated female, Red patches at back (two patches not fused), which segregated in a 1:1:1:1 ratio for Yellow, the parental phenotype, Red front + back and Red ring. Given what we can deduce about the

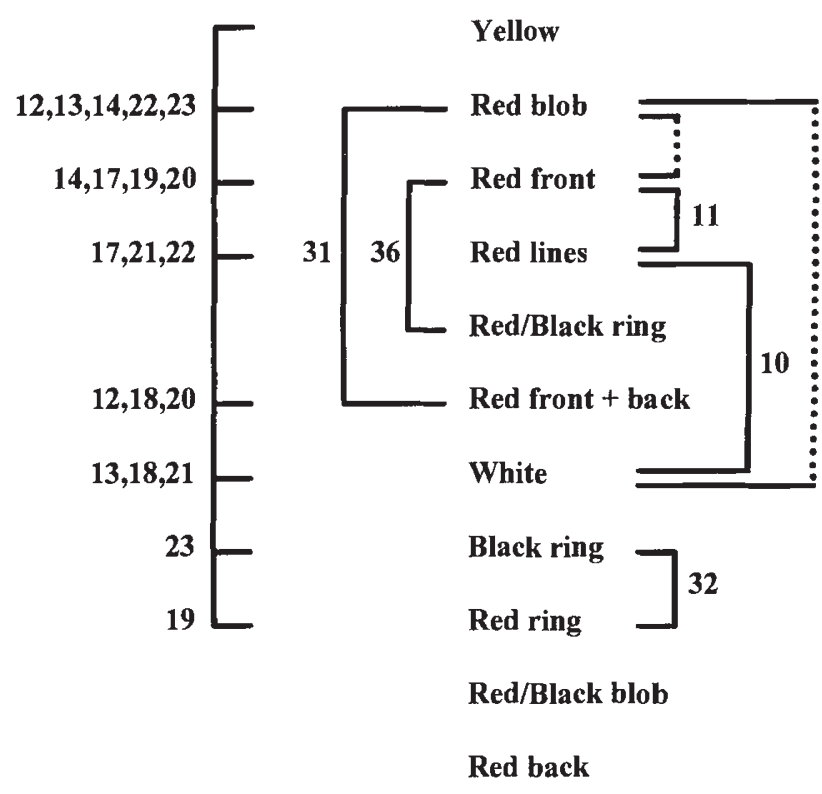

Fig. 1 Summary diagram showing the allelic nature of the opisthosomal colour morphs of Theridion grallator.

Numbers refer to crosses detailed in Tables 1 and 2. Lines join morphs shown to be allelic by the cross(es) specified. Morphs joined by dotted lines are shown to be allelic in interisland crosses (Oxford \& Gillespie, 1996b). nature of dominance relationships among the colour morphs (see below) these results are difficult to interpret on the basis of a single-pair mating. They are, however, perfectly consistent with a double mating in which the two males contributed equally to the progeny. It may be mere coincidence that these two matings showing unexpected progeny phenotypes or ratios involve Red back (or similar) females. Further crosses involving this morph are clearly necessary.

Figure 2 summarizes information on the dominance relationships within the patterned morphs, all of which are dominant to Yellow. The dominance hierarchy can be explained for the most part by the superimposition of one pattern over another. Thus Red blob, in which the pigment occupies the entire dorsal area, is dominant to Red lines, Red front+ back, Red front, Black ring and Red/Black ring, in which red or black pigment covers a lesser area. Codominance occurs in heterozygotes for morphs in which the areas of pigmentation do not fully overlap. For example, a combination of Red lines and Red front + back yields a Red ring morph (Plate $1 \mathrm{~m})$. Likewise, in some broods segregating for heterozygotes for Red lines and Red front, the area of pigment at the anterior of the pigmented lines is much wider, as would be expected if the two constituent patterns were superimposed. One such putative heterozygote was shown to be so by backcrossing to Yellow (Table 1, no. 4) - the sole offspring to survive was Red front. In other broods this codominance is not so obvious and may depend on the shape of the pigment field of the Red front morph. From the point of view of dominance, the White morph is intriguing. It is usually fully dominant to Red blob and to Red front + back, but codominant to Red lines. As mentioned above, the white pigment is produced within a different tissue from the red and black pigments, and presumably exerts an inhibitory effect on the synthesis of xanthommatin in the hypodermis above. This inhibition appears to be less around the edges of the guanine patch because in the White morph this is usually marked with black pigmentation (Plate $1 \mathrm{~h}$ ). It is here that the red pigment of the Red lines phenotype appears in White/Red lines heterozygotes. Occasionally in White/Red blob heterozygotes a black area, sometimes with a red rim, is present in the centre of the white shield. The fact that phenotypes of this sort are heterozygotes has been demonstrated in interisland crosses (Oxford \& Gillespie, 1996b). They have also been identified in the wild (Gillespie \& Tabashnik, 1989) 


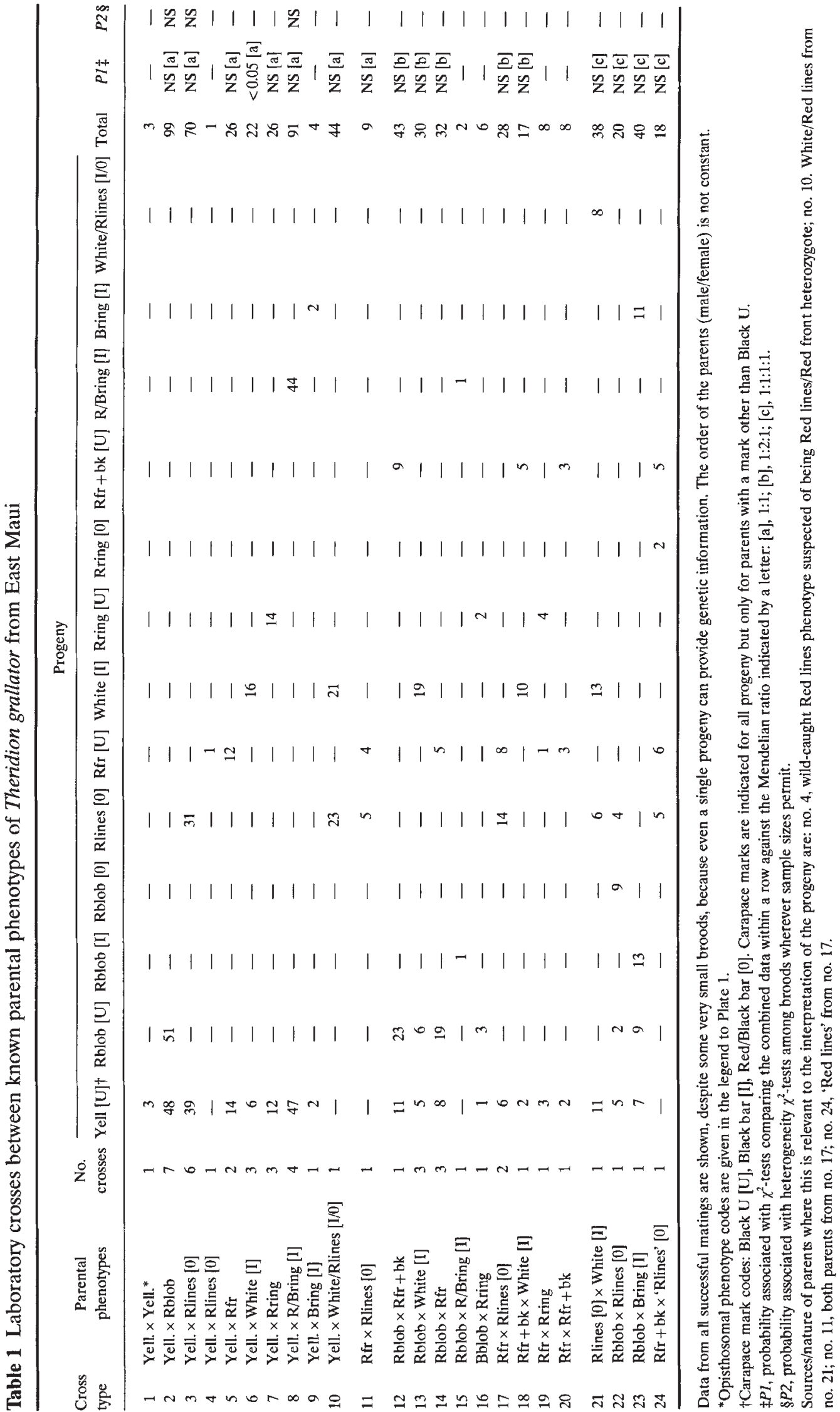




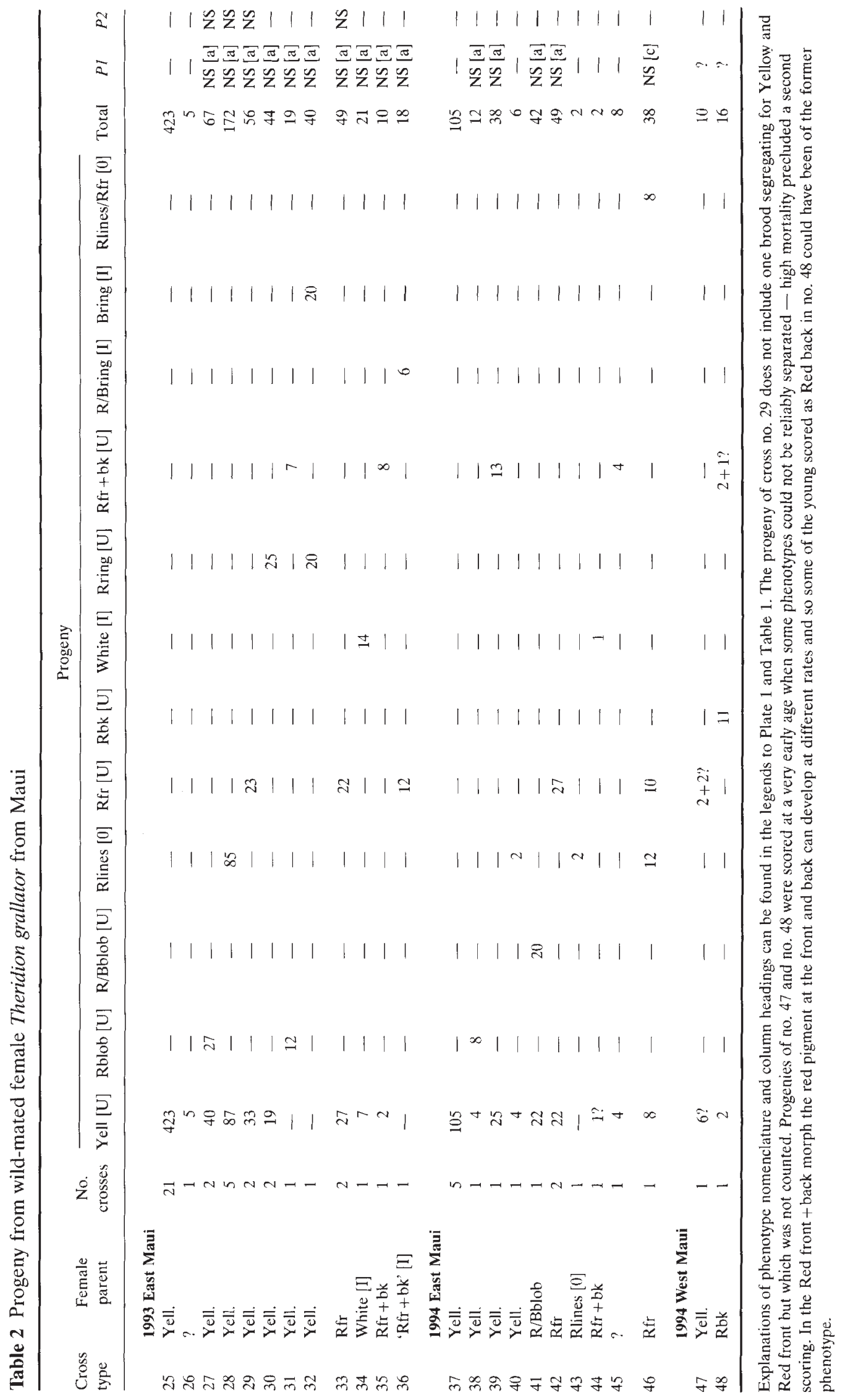

(C) The Genetical Society of Great Britain, Heredity, 76, 238-248. 


\section{Genetics of carapace patterns - Maui}

Three carapace patterns are recognized, as described above. Crosses described in Tables 1 and 2 provide information on the allelism and dominance of these phenotypes, which is summarized in Fig. 3. Allelism for all patterns is suggested by the crosses indicated in Fig. 3. All crosses between known Black $U$ patterns yielded the same in all the progeny (Table 1, nos 1, 2, 5, 7, 12, 14, 16, 19 and $20)$ whereas crosses involving a Black $U$ morph and either a Black bar or a Red/Black bar gave progeny that segregated 1:1 for Black $U$ and the other parental pattern (Table 1, nos 3, 8, 9, 11, 13, 17, 18, and 22-24). These matings are consistent with Black $U$ being bottom recessive to the other patterns. Critical crosses confirming this hypothesis are indicated in Fig. 3. Matings also show that Red/Black bar and Black bar are codominant, producing a pattern in which a mixture of red and black pigments occurs at the anterior end of the carapace in heterozygotes.

\section{Genetics of opisthosomal patterns - Moloka'i}

Few broods from this population have been reared so far; details are given in Table 3. A novel opisthosomal morph is represented here that is absent from the Waikamoi population on Maui (for a brief description, see legend to Table 3). Little can be deduced from these data except that (i) patterns segregate in Mendelian ways with, in one case (no. 51), the novel parental phenotype appearing in the progeny, and (ii) Red blob and Red front appear to be allelic and both are dominant to Yellow (no. 50). Of the rather few individuals raised to a stage at which sex could be determined, there were no indications that morphs were differentially distributed between males and females, an observation consistent with data from natural populations. In all cases carapace marks were of the basic Black U type.

\section{Discussion}

The results presented above show that the exuberant colour polymorphism of the Hawaiian happy-face spider is controlled by a rather simple mode of inheritance, at least in the Maui population that formed the focus of this study. The genetic mechanism underlying the diverse array of opisthosomal patterns is consistent with a model of multiple alleles at a single locus. There is no compelling evidence from the present matings that more than one locus is involved although the additive nature of the pattern elements from some morphs might

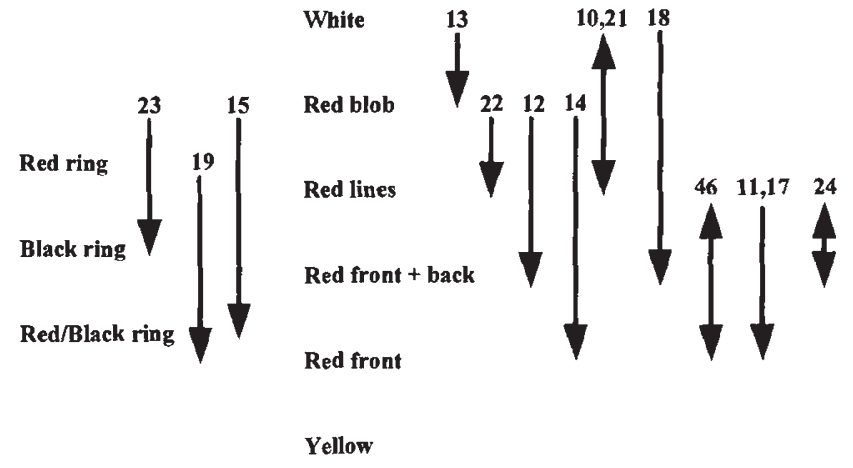

Fig. 2 Summary diagram showing the dominance relationships among the patterned opisthosomal morphs of Theridion grallator. Numbers refer to crosses detailed in Tables 1 and 2 . Arrows link pairs of morphs and show the direction of dominance, the morph at the arrowhead being recessive, e.g. White is dominant to Red blob. Double arrows indicate codominance. All patterned morphs are dominant to Yellow. No data are available on the dominance relationships of Red/Black blob and Red back, except that they appear to be dominant to Yellow.

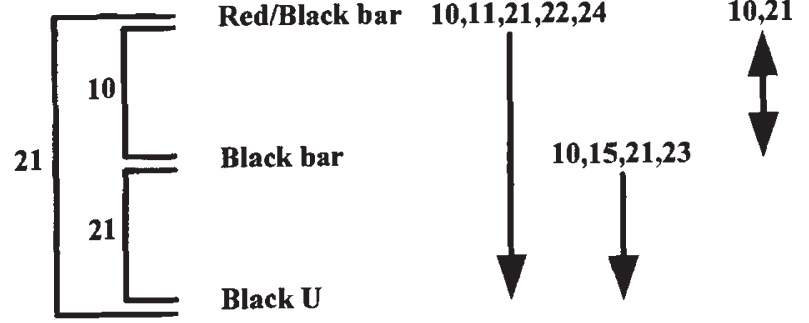

Fig. 3 Summary diagram indicating patterns of allelism and dominance for carapace morphs of Theridion grallator. Numbers refer to specific crosses in Tables 1 and 2; other conventions are as in Figs 1 and 2.

suggest the possibility of two closely linked loci. For example, Red front and Red back contain pigmented patterns which are combined in Red front + back, yet the latter apparently segregates as an allele of Red front. There are no indications of any bias in the frequencies of specific patterns between the sexes either in the laboratory or in the field, suggesting that the locus concerned is not sex-linked or particular morphs sex-limited. The dominance hierarchy among morphs indicates that pigment patterns determined by each allele are more-or-less superimposed. Thus the heterozygote between Red front + back and Red lines produces an opisthoso- 
Table 3 Results of laboratory crosses and progeny of a wild-mated female Theridion grallator from Moloka'i

\begin{tabular}{llccccccr}
\hline & & \multicolumn{9}{c}{ Progeny } \\
\cline { 3 - 6 } $\begin{array}{l}\text { Cross } \\
\text { type }\end{array}$ & $\begin{array}{l}\text { Parental } \\
\text { phenotypes }\end{array}$ & $\begin{array}{c}\text { No. } \\
\text { crosses }\end{array}$ & Yell. [U] & Rblob [U] & Rfr [U] & R@fr [U] & Total & $P 1$ \\
\hline 49 & Yell. $\times$ Rfr & 1 & 16 & - & 9 & - & 25 & NS [a] \\
50 & Yell. $\times$ Rblob & 1 & - & 4 & 5 & - & 9 & - \\
51 & R@fr* & 1 & 6 & - & - & 10 & 16 & NS [a] \\
\hline
\end{tabular}

Explanations of phenotype nomenclature and column headings can be found in the legends to Plate 1 and Table 1. *The Red at front (R@fr) morph (no. 51) was like a Red front but with the red areas not fused in the midline. The equivalent morph in the progeny resembled the female parent exactly.

mal phenotype almost identical to Red ring (Plate $1 \mathrm{~m})$. The complete dominance of white over almost all other morphs seems to be a result of suppression by the guanine of pigment synthesis in the overlying hypodermis. Information on both carapace and opisthosomal morphs allows the identification of heterozygotes for both systems. Thus, Red blob individuals with a Red/Black bar carapace mark (Table 1, no. 22) indicate that these spiders must be heterozygous for the Red blob and Red lines alleles and show that Red blob is dominant to Red lines, and that the Red/Black bar carapace mark is dominant to the Black U. Odd combinations of carapace and opisthosomal morphs can also indicate situations where the latter is not fully expressed. For example, the wild mated 'Red front + back' female (Table 2, no. 36) unusually had a Black bar carapace mark rather than the normal Black U. Her progeny demonstrated that she was not a Red front + back at all but a heterozygote for Red front and Red/Black ring with the mid-part of the ring missing.

Suppression of pigmentation by underlying guanine in the case of the White morph is an exception rather than a rule. As mentioned, the basic ground colour of $T$. grallator is a translucent yellow. On the opisthosoma, wherever red or black pigments are deposited they are always underlain by a corresponding pattern of guanine (Plate 1). The pigmented patterns are thus displayed to maximum effect against a white backcloth and appear as opaque areas on the translucent background. Therefore, except for White, guanine is positively associated with the pigmentation of patterned morphs. This highly specific correspondence between hypodermal pigmentation and the deposition of guanine in deeper, and morphologically unconnected, tissues raises interesting questions regarding the nature of the synchronization of pattern formation in development. During embryogenesis the hypodermis is derived from the ectoderm whereas the mid-gut tissues are endodermal in origin (Foelix, 1982).
Observations on pattern formation in broods during growth suggest that, in general, there is no consistent order in the appearance of pigmentation and of guanine within particular pattern elements. In some cases guanine defines the pattern first, in other cases this is indicated by pigmentation. This is the first recorded instance in which both guanine and pigmented patterns cosegregate as elements in a colour polymorphism in spiders, although admittedly rather few cases have received adequate study. In Enoplognatha ovata (Theridiidae), perhaps the best worked spider from a genetical point of view, pigmentation is displayed on a uniform background of guanine which covers the entire dorsal and lateral surfaces of the opisthosoma in all colour morphs (Oxford, 1983). Cases of specific associations of guanine deposits with key pigmented areas of the opisthosoma are known in other spiders, but there is no indication that the species are polymorphic in this respect. For example, in the adult female Latrodectus mactans (the black widow spider) the opisthosoma is jet-black except for a red hour-glass pattern on the ventral surface beneath which is an exactly corresponding area of guanine. Guanine deposits are found under no other areas of hypodermis (Oxford, unpublished). At this stage, one can only guess at the ontogenetic coupling of guanine and pigment deposits in $T$. grallator. The simplest explanation is that they are controlled by pleiotropic effects of the alleles acting on co-ordinated patterngenerating elements within the various tissues involved. Given the disparate origins of these tissues, patterns must be laid down relatively late in development. Because a one-to-one coupling of pigment and underlying guanine is clearly not a necessary condition of pattern formation in spiders (e.g. in the White morph of T. grallator, in E. ovata and under the black pigment of L. mactans) its presence here seems to indicate a device to maximize the contrast between red- and black-pigmented areas and the translucent yellow background of the 
spider's body. In other words, it strongly suggests that the coloured patches have evolved for their visual effects, a conclusion consistent with other evidence (Gillespie \& Oxford, in preparation; Gillespie, Oxford \& Marumoto, in preparation).

In $T$. grallator, patterns on the carapace are also polymorphic. They too appear to be controlled by alleles at one locus, although again, determination at more than one closely linked locus cannot be eliminated. The dominance hierarchy of the morphs is consistent with the superimposition of one pattern on another. The very tight association between carapace pattern and opisthosomal pattern shown in the field and in laboratory broods suggests two possible hypotheses; either the carapace patterns represent pleiotropic effects of the alleles controlling opisthosomal patterns, or else two loci are involved, one determining the pattern of the carapace and the other that of the opisthosoma. The first hypothesis is least favoured for two reasons. First, very different opisthosomal patterns are associated with identical carapace patterns. Thus Black $U$ on the carapace is found in opisthosomal morphs ranging from unpatterned (Yellow), with no red pigment, through to the most patterned, Red blob, with the entire dorsal surface pigmented. Likewise, Black bar on the carapace is associated with Red/Black and Black ring morphs and with White. There seems no obvious reason, for example coupled with the colour or degree of pigmentation, why such different opisthosomal patterns should lead to identical carapace markings. Secondly, in the West Maui population some Red/Black ring morphs, which appear absolutely identical to those from East Maui, are associated with Black $U$ rather than Black bar carapace marks. Because Black $U$ has been shown to be recessive to other carapace marks, these individuals cannot be heterozygotes for any other pattern. Both of these observations suggest that the two-locus model is more likely to be correct. Laboratory matings show that the loci concerned must be tightly linked and this, in terms of proximate causation, would explain the extreme linkage disequilibrium seen in the field. Whether the loci have evolved close linkage for adaptive reasons is unknown, although there are well understood precedences for such processes involving visible characters, e.g. in the evolution of Batesian mimicry in Papilio butterflies (Clarke \& Sheppard, 1960a, 1971, 1972; Clarke et al., 1968) and of colour and banding patterns in Cepaea snails (Jones et al., 1977). The functioning of the loci is sufficiently similar for it to be difficult to differentiate between tandem duplication of an ancestral locus, with a subsequent major shift in tissue specificity, and genomic processes increasing linkage between initially dispersed loci. Majerus (1994, p. 251), however, in discussing the tight linkage between a locus controlling pronotal pattern and one controlling the colour and pattern on the elytra of Adalia bipunctata, a close parallel to the present situation, concluded that 'at least part of the supergene did not result from gene duplication'. If tight linkage has evolved in T. grallator, this provides further evidence for the adaptive nature of the polymorphic variation.

There is no evidence that opisthosomal or carapace patterns are modified by the genetic background, at least within populations. In all crosses the fine details of the parental morphs are faithfully reproduced in the equivalent morphs appearing in the progeny. Morphs have been grouped here according to their general appearance, but within a class, e.g. Red front, the shape and size of the red patch, and whether it is rimmed with black pigment or not, varies greatly both within and among populations. These minor variants may result from (linked) modified loci acting on the principal alleles or they may represent true alleles at the major colour locus or loci. In either case, the number of effective alleles and colour morphs present in a population is likely to be very high indeed.

\section{Acknowledgements}

The work reported here was supported in Hawai'i by National Science Foundation Grant DEB 9207753 to R.G.G and G.S.O., and in York by Natural Environment Research Council Grant GR9/1530 to G.S.O. Additional support to enable G.S.O. to work in Hawai'i during 1993 is gratefully acknowledged from the British Ecological Society, the Royal Society, the Bonhote Bequest, the Percy Sladen Memorial Fund and the University of York. We thank Peter Follett, Roma Oxford, George Roderick and An-Ming Tan for assistance in the field, and Patrick Conant, Linden Doescher, Kelvin Kanegawa and Bruce Tabashnik for supplying diamond-back moths, $D$. grimshawi and $D$. melanogaster prey. The late Keith Partridge provided essential logistical support in York. For assistance in gaining access to collecting sites we would like to thank the Nature Conservancy of Hawai'i, in particular Ed Misaki (Kamakou Preserve, Moloka'i), Paul Higashino and Mark White (Waikamoi Preserve, East Maui) and the company Maui Land and Pineapple, in particular Randy Bartlett (Pu'u Kukui, West Maui). Thanks also to Bill Mull and Sam Gon for discussion and 
two anonymous referees for helpful comments on the manuscript.

\section{References}

CARSON, H. L. AND ClaGUE, D. A. 1995. Geology and biogeography of the Hawaiian islands. In: Wagner, W. L. and Funk, V. A. (eds) Hawaiian Biogeography: Evolution on a Hot Spot Archipelago, pp. 14-29. Smithsonian Institution Press, Washington, DC.

ClARKE, C. A. AND SHEPPARD, P. M. 1960a. Super-genes and mimicry. Heredity, 14, 175-185.

ClaRKe, C. A. AND SHEPPARD, P. M. 1960b. The evolution of dominance under disruptive selection. Heredity, 14, $73-87$.

CLARKE, C. A. AND SHEPPARD, P. M. 1971. Further studies on the genetics of the mimetic butterfly Papilio memnon L. Phil. Trans. R. Soc, B, 263, 35-70.

CLARKE, C. A. AND SHEPPARD, P. M. 1972. The genetics of the mimetic butterfly Papilio polytes L. Phil. Trans. R. Soc. B, 263, 431-458.

ClARKE, C. A., SHEPPARD, P. M. AND THORNTON, 1. W. B. 1968. The genetics of the mimetic butterfly Papilio memnon L. Phil. Trans. R. Soc. B, 254, 37-89.

FOELIX, R. F. 1982. Biology of Spiders. Harvard University Press, Cambridge, MA.

GILLESPIE, R. G. 1990. Costs and benefits of brood care in the Hawaiian happy face spider Theridion grallator (Araneae, Theridiidae). Am. Midl. Nat., 132, 236-243.

GILLESPIE, R. G. AND TABASHNIK, B. E. 1989. What makes a happy face? Determinants of colour pattern in the Hawaiian happy face spider Theridion grallator (Araneae, Theridiidae). Heredity, 62, 355-363.

GILLESPIE, R. G. AND TABASHNIK, B. E. 1990. Maintaining a happy face: stable colour polymorphism in the spider Theridion grallator (Araneae, Theridiidae). Heredity, 65, $67-74$.

GON, s. M. 1985. Comparative Behavioral Ecology of the Spider Theridion grallator (Simon) (Araneae: Theridiidae) in the Hawaiian Archipelago. Ph.D. Thesis, University of California, Davis, CA.

GULICK, J. T. 1872 . On the variation of species as related to their geographical distribution, illustrated by the Achatinellinae. Nature, 6, 222-224.

GULICK, J. T. 1873. On diversity of evolution under one set of external conditions. J. Linnaean Soc. Zool., 11, 496-505.

HOLL, A. 1987. Coloration and chromes. In: Nentwig, W. (ed.). Ecophysiology of Spiders, pp. 16-25. SpringerVerlag, Berlin.

JONES, J. S., LEITH, B. H. AND RAWLings, P. 1977. Polymorphism in Cepaea: a problem with too many solutions? Ann. Rev. Ecol. Syst., 8, 109-143.

Majerus, M. E. N. 1994. Ladybirds. Harper Collins Publishers, London.

OXFORD, G. s. 1983. Genetics of colour and its regulation during development in the spider Enoplognatha ovata (Clerck) (Araneae: Theridiidae). Heredity, 51, 621-634.

OXFORD, G. S. AND GILLESPIE, R. G. 1996a. Quantum shifts in the genetic control of a colour polymorphism in Theridion grallator (Araneae: Theridiidae), the Hawaiian happy-face spider. Heredity, 76, 249-256.

OXFORD, G. S. AND GILLESPIE, R. G. 1996b. The effects of genetic background on the island-specific control of a colour polymorphism in Theridion grallator (Araneae: Theridiidae), the Hawaiian happy-face spider. Heredity, 76, 257-266.

SELIGY, V. L. 1972. Ommochrome pigments of spiders. Comp. Biochem. Physiol., 42A, 699-709. 